\title{
GMAA: A DSS Based on the Decision Analysis Methodology - Application Survey and Further Developments
}

\author{
Antonio Jiménez and Alfonso Mateos \\ Universidad Politécnica de Madrid \\ Spain
}

\section{Introduction}

Most of the real decision-making problems that we face nowadays are complex in the sense that they are usually plagued with uncertainty, and we have to take into account several conflicting objectives simultaneously. Decision support systems (DSS) play a key role in these situations helping decision makers (DMs) to structure and achieve a better understanding of the problem to make a final decision.

A number of multicriteria decision analysis techniques have underpinned the development and implementation of DSS in the last few decades (Figueira et al. (eds.), 2005). They include the analytic hierarchy process (Saaty, 1980; Pérez et al., 2006; Bana e Costa \& Vansnick, 2008); outranking methods, especially ELECTRE (Roy, 1996; Figueira et al., 2005; Wang \& Triantaphyllou, 2008); PROMETHEE, proposed in (Brans \& Vincke, 1985; Brans et al., 1996; Brans \& Mareschal, 2005; Mareschal et al., 2008), and their variants; or approaches based on multi-attribute utility theory (MAUT) (Keeney \& Raiffa, 1993; Clemen 1996).

Corner and Kirkwood and Keefer et al. offer a systematic review of applications fields where DA methods were used and reported in operations research journals between 1970 and 2001 (Corner \& Kirkwood, 1991; Keefer et al., 2004).

OR/MS Today published its tenth biennial decision analysis software survey in 2010 (Bucksaw, 2010). These surveys include broad-based information about available DSSs and their features.

The decision analysis $(D A)$ methodology is widely used within MAUT. The goal of DA is to structure and simplify the task of making hard decisions as much as possible (Keeney \& Raiffa, 1976; Clemen, 1996, Kirkwood, 1997). DA was developed on the assumption that the alternatives will appeal to the expert, depending on the expert preferences concerning the possible performances and the likelihood of each alternative performing in this manner.

What makes $D A$ unique is the way in which these factors are quantified and formally incorporated into the problem analysis. Existing information, collected data, models and professional judgments are used to quantify the likelihoods of a range of performances, whereas utility theory is used to quantify preferences.

The usual or traditional approach to $D A$ calls for single or precise values for the different model inputs, i.e., for the weight and utility assessments, as well as for the multi-attributed performances of the alternatives. However, most complex decision-making problems 
involve imprecise information. Several reasons are given in the literature to justify why a DM may wish to provide incomplete information (Weber, 1987; Sarabando \& Dias, 2010). For instance, regarding alternative performances, some parameters of the model may be intangible or non-monetary as they reflect social or environmental impacts. Also, the performances may be taken from statistics or measurements, and the information that would set the value of some parameters may be incomplete, not credible, contradictory or controversial. At the same time, it is often not easy to elicit precise weights, which may be represented by intervals, probability distributions and even fuzzy values, or just satisfying ordinal relations. DMs may find it difficult to compare criteria or not want to reveal their preferences in public. Furthermore, the decision may be taken within a group, where the imprecision of the preferences is the result of a negotiation process.

This situation where it is not possible to indicate precise values for the parameters and quantities involved is often referred to as decision-making with imprecise information, with incomplete information or with partial information, together with incomplete knowledge or linear partial information (Kmietowicz \& Pearman, 1984; Kirkwood \& Sarin, 1985; Hazen, 1986; Ríos Insua \& French, 1991).

A lot of work on MAUT has dealt with incomplete information. (Sage \& White, 1984) proposed the model of imprecisely specified ISMAUT, where preference information about both weights and utilities is assumed not to be precise. (Malakooti, 2000) suggested a new efficient algorithm for ranking alternatives when there is incomplete information about the preferences and the performance of the alternatives. This involves solving a single mathematical programming problem many times. (Ahn, 2003) extended Malakooti's work. (Eum et al., 2001) provided linear programming characterizations of dominance and potential optimality for decision alternatives when information about performances and/or weights is incomplete, extended the approach to hierarchical structures (Lee et al., 2002; Park, 2004), and developed the concepts of weak potential optimality and strong potential optimality (Park, 2004). More recently, (Mateos et al., 2007) considered the more general case where imprecision, described by means of fixed bounds, appears in alternative performances, as well as in weights and utilities.

The stochastic multicriteria acceptability analysis (SMAA) and SMAA-2 methods (Lahdelma \& Salminen, 1998; 2001) were developed for support in discrete group decision-making problems, where weight information is absent. These methods explore the weight space in order to describe the ratings that would make each alternative the preferred one. This situation was also considered by other authors (Bana e Costa, 1986; Charnetski \& Soland, 1978; Nijkamp et al., 1990; and Voogd, 1983).

(Sarabando \& Dias, 2010) gives a brief overview of approaches proposed by different authors within the MAUT and MAVT (multi-attribute value theory) framework to deal with incomplete information.

\section{The GMAA decision support system}

The generic multi-attribute analysis (GMAA) system is a PC-based DSS based on an additive multi-attribute utility model that is intended to allay many of the operational difficulties involved in the DA cycle (Jiménez et al., 2003; 2006).

This cycle can be divided into four steps: 1) structuring the problem (which includes specifying objectives, building a value hierarchy and establishing attributes for the lowestlevel objectives); 2) identifying the feasible alternatives, their performances and uncertainty 
(if necessary); 3) quantifying preferences (which includes the assessment of the component attribute utilities, as well as the weights representing the relative importance of criteria); and 4) evaluating alternatives and performing sensitivity analysis (SA).

The GMAA system accounts for uncertainty about the alternative performances. Quantifying preferences involves assessing component utilities, which represent the DM's preferences over the possible attribute performances, and eliciting weights, which account for the relative importance of criteria.

The GMAA system provides four procedures for assessing component utilities: 1) construct a piecewise linear imprecise utility function, 2) construct an imprecise utility function with a gamble-based method (Jiménez et al., 2003), 3) assign imprecise utilities to discrete attribute values and 4) directly provide subjective values.

There are two main ways of representing the relative importance of criteria. The first is to preemptive order attributes (Adelbratt \& Montgomery, 1980), and the second is to use attribute weights. The second option is more widespread and is used in the GMAA system. Different methods have been proposed to elicit weights by different authors, such as DIRECT point allocation, simple multi-attribute rating technique - SMART - (Edwards, 1977), SWING weighting (von Winterfeldt \& Edwards, 1986; Edwards \& Barron, 1994), SMART using swings - SMARTS - (Edwards \& Barron, 1994), SMART exploiting ranks - SMARTER Edwards \& Barron, 1994), TRADE-OFFS weighting (Keeney \& Raiffa, 1993), pricing out method (Keeney \& Raiffa, 1993), analytic hierarchy process -AHP- (Saaty, 1980), or preference programming (Salo \& Hämäläinen, 1995). The GMAA system provides DIRECT point allocation and TRADE-OFFS weighting.

The GMAA system accounts for incomplete information about the DM's preferences through value intervals as responses to the probability questions that the DM is asked, leading to classes of utility functions and weight intervals. This is less demanding for a single DM and also makes the system suitable for group decision support, where individual conflicting views in a group of DMs can be captured through imprecise answers.

An additive multi-attribute utility function is used to evaluate the alternatives, taking the form

$$
u\left(S^{j}\right)=\sum_{i=1}^{n} w_{i} u_{i}\left(x_{i}^{j}\right)
$$

where $w_{i}$ is the $i$ th attribute weight, $x_{i}$ is the performance for alternative $S j$ in the $i$ th attribute and $u_{i}\left(x_{i j}\right)$ is the utility associated with the above performance.

For the reasons described in (Raiffa, 1982; Sterwart, 1996), the additive model is considered to be a valid approach in most practical situations. It is used to assess, on the one hand, average overall utilities, on which the ranking of alternatives is based and, on the other, minimum and maximum overall utilities, which give further insight into the robustness of this ranking.

The GMAA provides several types of SA. It can assess the stability weight interval for any objective at any level in the hierarchy. This represents the interval where the average normalized weight for the considered objective can vary without affecting the overall ranking of alternatives or just the best ranked alternative.

On the other hand, the assessment of non-dominated and potentially optimal alternatives (Mateos et al., 2007) takes advantage of the imprecise information gathered during the assignment of 
component utilities and weights and the performance of the entered uncertain alternatives to definitely reject poor alternatives, mainly by discarding dominated and/or nonpotentially optimal alternatives.

The GMAA system computes the potentially optimal alternatives among the non-dominated alternatives because these are alternatives that are best ranked for at least one combination of the imprecise parameters, i.e., weights, component utility functions and alternative performances.

Finally, Monte Carlo simulation techniques enable simultaneous changes of the weights and generate results that can be easily analyzed statistically to provide more insight into the multi-attribute model recommendations (Mateos el at, 2006). While the simulation is running, the system computes several statistics about the rankings of each alternative, like mode, minimum, maximum, mean, standard deviation and the 25th, 50th and 75th percentiles. This information can be useful for discarding some available alternatives, aided by a display that presents a multiple boxplot for the alternatives.

The GMAA system provides three general classes of simulation. In the random weights option, weights for the attributes are generated completely at random, which means that there is no knowledge whatsoever of the relative importance of the attributes. In the rank order weights option, attribute weights are randomly generated preserving a total or partial attribute rank order, which places substantial restrictions on the domain of possible weights that are consistent with the DM's judgement of criteria importance, leading to more meaningful results. Finally, in the response distribution weights option, attribute weights are now randomly assigned values taking into account the normalized attribute weight intervals provided by the DM in the weight elicitation methods.

The Universidad Politécnica de Madrid registered the GMAA system and a free version (installation package and user's guide) is available for academic purposes at http://www.dia.fi.upm.es/ ajimenez/GMAA.

\section{Real application to complex decision-making problems}

GMAA has proved to be useful for solving complex decision-making problems in different areas. We summarize below some of the problems in which GMAA was used as a key part of the decision-making process.

\subsection{Selection of intervention strategies for the restoration of aquatic ecosystems contaminated by radionuclides}

The first problem in which the GMMA system was used was to evaluate intervention strategies for the restoration of aquatic ecosystems contaminated by radionuclides.

This problem was studied in depth as part of several European projects in which we participated: MOIRA (A model-based computerized system for management support to identify optimal remedial strategies for restoring radionuclide contaminated aquatic ecosystem and drainage areas) (Monte et al., 2000), COMETES (implementing computerized methodologies to evaluate the effectiveness of countermeasures for restoring radionuclide contaminated freshwater ecosystems) (Monte et al., 2002), EVANET-HYDRA (evaluation and network of EC-decision support systems in the field of hydrological dispersion models and of aquatic radioecological research), and EURANOS (European approach to nuclear and radiological emergency management and rehabilitation strategies). 
Throughout these projects, a synthetic, flexible and user-friendly computerized decision support system, MOIRA, was implemented and tested on several real scenarios. The system included a multi-attribute analyses module for the global assessment of the effectiveness of the intervention strategies. This module was the origin of the GMAA system, which was finally built into the last versions of the MOIRA system.

The selection of intervention strategies was based on environmental models for predicting the migration of radionuclides through freshwater and coastal ecosystems and the effects of feasible countermeasures on contamination levels. Moreover, other social and economic criteria were taken into account.

Several real scenarios contaminated as a consequence of the Chernobyl accident were analysed, like lake Øvre Heimdalsvatn (Jiménez et al., 2003), located in Oppland county (Norway), lake Kozhanovskoe (Ríos Insua et al., 2004), located in the region of Bryansk (Russia), and lake Svyatoye in Belarus (Ríos Insua et al. 2006).

Lake Svyatoye is located $237 \mathrm{~km}$ from the Chernobyl nuclear power plant and $30 \mathrm{~km}$ southeast of Kostyukovichy (Belarus), and the ${ }^{137}$ Cs contamination in the area was over 1480 $\mathrm{kBq} / \mathrm{m}^{2}$. It is a collapse (karst) type lake. The maximum depth, at the center of the lake, is $5.2 \mathrm{~m}$. It has both precipitation and subsurface water supply and the water balance is controlled by evaporation and subsurface runoff.

According to the DA cycle, we started to build an objective hierarchy including all the key aspects to be considered in the problem, see Fig. 1.

Environmental Impact (Environ. Imp) is one of the main objectives of the decision analysis. It was divided into Lake Ecosystem Index (L.E.I.), a simple and rational approach for measuring the ecological status of a lake, and Radiation Dose to Biota (Dose to Fish). Social Impact (Social Imp.) was handled by two sub-objectives: minimizing impact on health (Dose to Man) and Living Restrictions (Living restr).

Regarding dose to man, we focused on the Dose to Critical Individuals (Dose Crit In), who should never receive radiation levels above thresholds for early health effects, and Collective Dose (Coll. Dose), which was linearly related to the increase in the risk of developing serious latent effects, mainly cancers. As regards living restrictions, other impacts were taken into consideration. These include countermeasures affecting the direct consumption of fish for food or its processing in the food industry, drinking water and water used by the food industry, the use of water for crops irrigation and the recreational uses of water bodies. For all these objectives, the attributes were the amount of fish affected by restrictions (Amount fish), as well as the duration of such restrictions (Ban Duration).

Finally, Economic Impact (Economic Im) was divided into Direct Effects (Direct Eff.), more amenable to quantification, and Intangible Effects (Intang. Eff.), like loss-of-image and adverse market reactions for the concerned area, which could also be subjectively valued by the user. The direct effects include the costs generated by the different bans or restrictions to normal living conditions, which can be sub-divided into Costs to the Economy (Cost to econ) and the more subjective costs of lost recreation, and Application Costs (Applic. Cost), i.e., costs of chemical and physical remedial countermeasures.

Taking into account expert knowledge and opinions, a set of seven intervention strategies were proposed for analysis, combining chemical countermeasures with fishing bans so as to reduce the radiological and environmental impact:

- No action (natural evolution of the situation without intervention).

- Potassium (15 tonnes of potassium chloride added to the lake in April 1987). 
- $\quad$ Fertilizer (800 kg of fertilizer added to the lake between April and July 1987-90).

- Food ban (fish consumption ban when ${ }^{137}$ Cs content in fish is $>1000 \mathrm{~Bq} / \mathrm{kg}$ ).

- $\quad$ Lake liming (15 tonnes of lime added to the lake in April 1987).

- Sediment removal $\left(250,000 \mathrm{~m}^{2}\right.$ of sediments down to a depth of $10 \mathrm{~cm}$ removed from the lake, between May-June 1990, i.e., 125,000 m²/month).

- Wetland liming (30 tonnes of lime added to the catchment in May 1987).

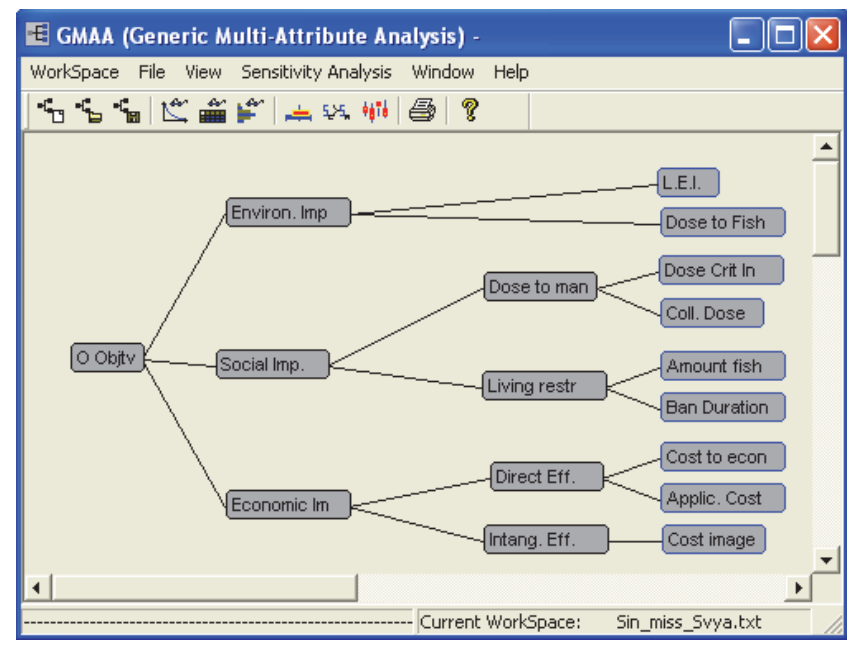

Fig. 1. Objectives hierarchy for lake Svyatoye

The impacts/performances of the intervention strategies were then established in terms of the attributes associated with the lowest-level objectives and described under uncertainty by vectors of values (see Table 3 in Ríos- Insua et al., 2006).

DM preferences were elicited according to DA cycle. An imprecise component utility function was assessed for each attribute, representing DM preferences concerning the respective possible attribute impacts. Fig. 2 shows the class of utility functions for the Dose to Critical Individuals.

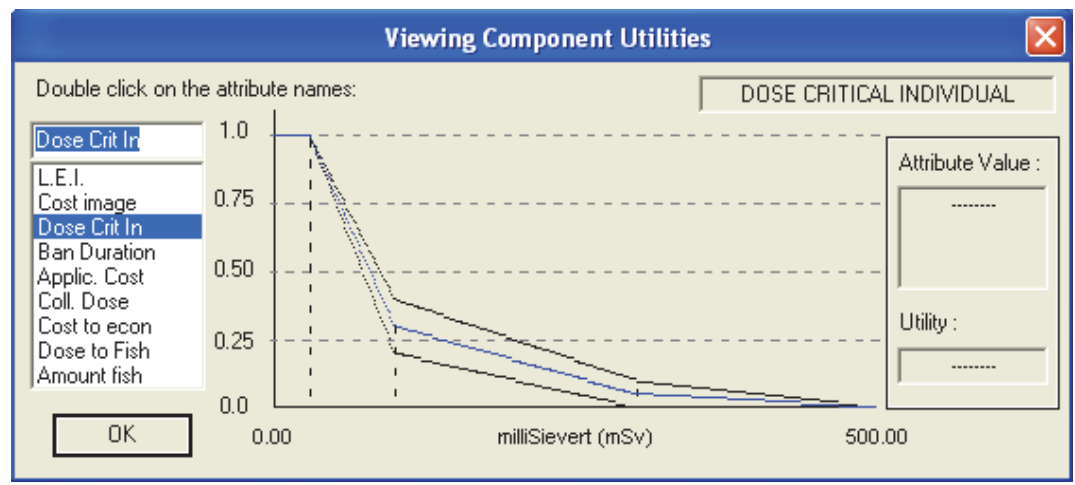

Fig. 2. Classes of utility functions for Dose to Critical Individuals 
On the other hand, objective weights representing their relative importance were elicited along the branches of the objectives hierarchy. Then, the attribute weights used in the additive multi-attribute utility model were assessed by multiplying the elicited weights in the path from the overall objective to the respective attributes, see Fig. 3. These attribute weights are indicators of the influence of the individual criteria on the decision.

The additive multi-attribute utility model, which demands precise values, was then used to assess, on the one hand, average overall utilities, on which the ranking of alternatives is based and, on the other, minimum and maximum overall utilities, which give further insight into the robustness of this ranking.

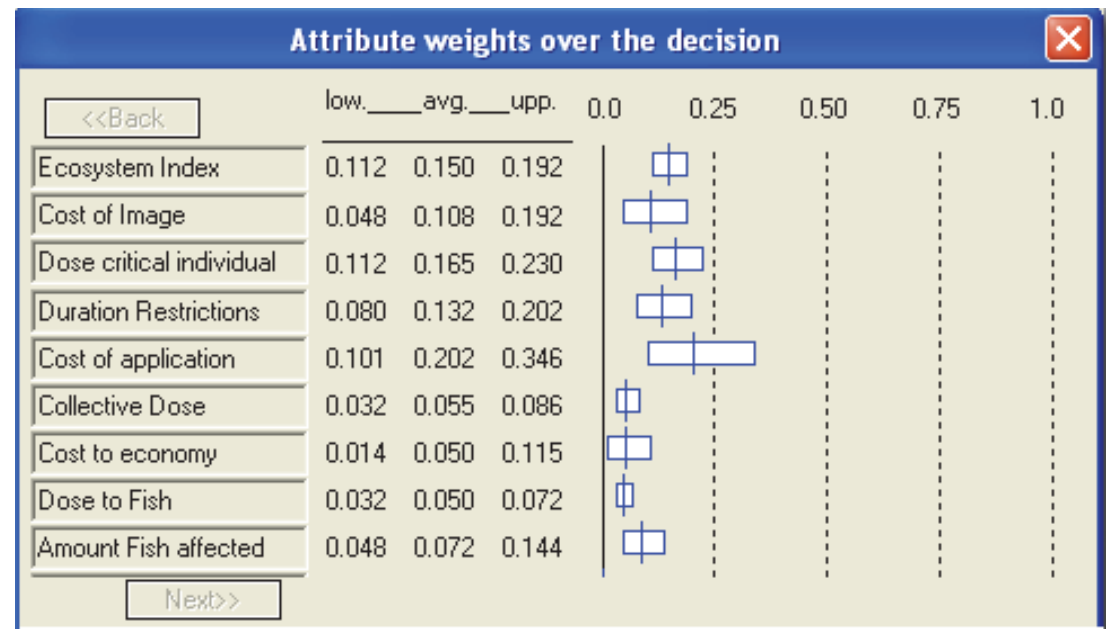

Fig. 3. Imprecise attribute weights in the selection of intervention strategies

Fig. 4 shows the ranking of the intervention strategies for lake Svyatoye, where the vertical white lines on each bar represent average utilities. The best-ranked intervention strategy was Potash with an average overall utility of 0.802 , followed by Lake Liming (0.754) and Wetland Liming (0.751), whereas the worst ranked option was Sediment Removal with a utility of 0.607.

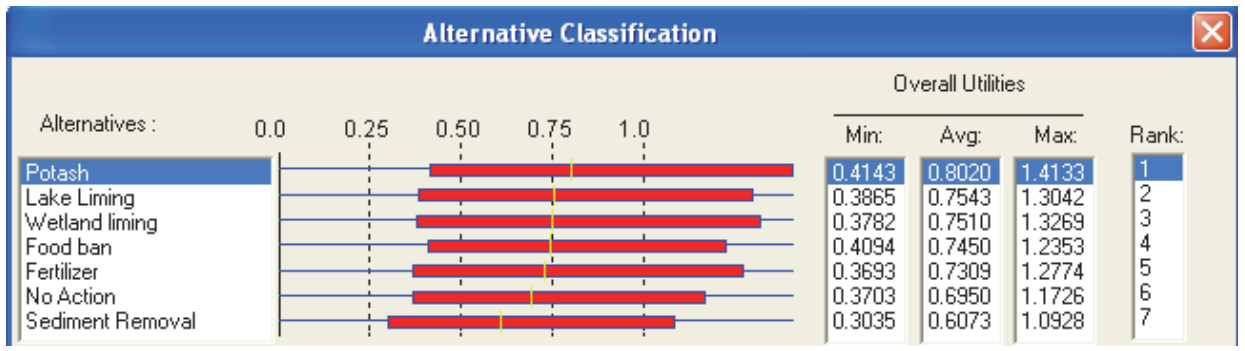

Fig. 4. Ranking of intervention strategies for lake Svyatoye

Looking at the overlapped utility intervals (robustness of the ranking of strategies), however, we concluded that the information obtained by this evaluation was not meaningful enough to definitively recommend an intervention strategy. Consequently, 
sensitivity analysis should be carried out to output further insight into the recommendations.

First, all the intervention strategies were non-dominated and potentially optimal, i.e., they were not dominated by any other strategy and best-ranked for at least one combination of the imprecise parameters, i.e., weights, component utilities and strategy impacts. Thus, we could not discard any of them from further consideration.

Then, Monte Carlo simulation techniques were applied. The response distribution weights option was selected, i.e., attribute weights were randomly assigned values taking into account the weight intervals provided by the DMs in weight elicitation, see Fig. 3. Fig. 5 shows the resulting multiple boxplot.

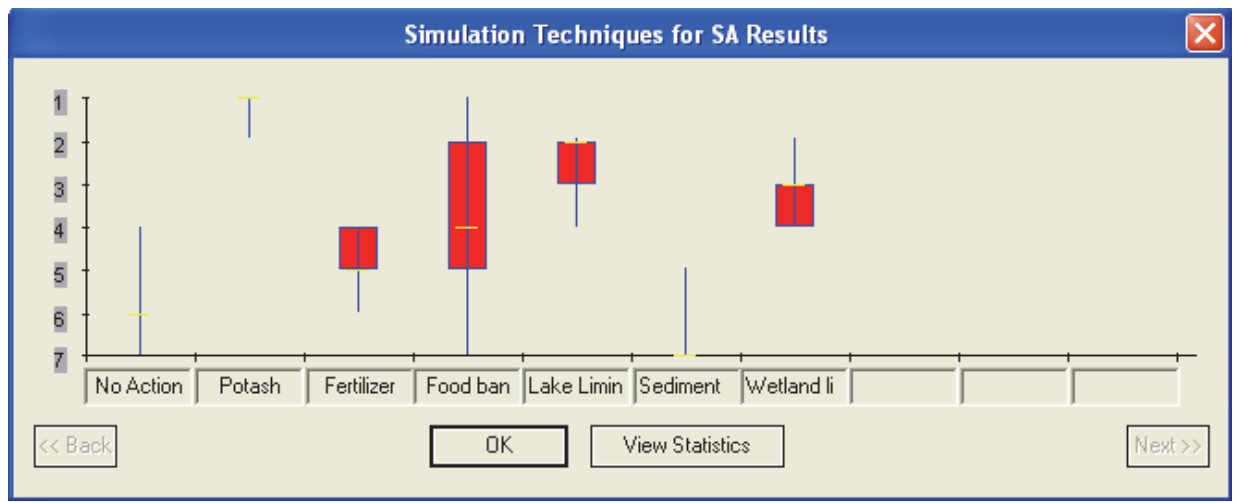

Fig. 5. Multiple boxplot with response distribution weights

Only two intervention strategies were best ranked for at least one combination of weights, Potash and Food Ban, but the worst classification for both was second and seventh, respectively. Moreover, the mean classifications were 1.065 and 3.785, respectively, indicating that the intervention strategy that should be definitively recommended was Potash.

\subsection{Selection of a supplier for cleaning services in an underground transportation company}

The GMAA system was also used to select a supplier for cleaning services in a European public underground transportation company (Jiménez et al., 2007).

From a cost management perspective, the cleaning service represents a sizeable part of the operating costs of an underground transportation service, accounting for close to $10 \%$ of total annual operating expenses. Inherent service intangibility, heterogeneity and inseparability greatly constrain service acquisition and management (Zeithaml et al., 1990). For the purpose of determining the most economically advantageous suppliers, several conflicting criteria were taken into account simultaneously to provide the most relevant information about what other factors, in conjunction with prices, to apply during the awardof-contract process, like delivery conditions and human resources, technical merit and resources, quality control procedures, etc., according to the public procurement policies and legislation for national and European public organizations. These criteria were compiled as a result of a team effort, including procurement and technical experts from the 
organizational areas responsible for cleaning services, finance and other departments or representatives, such as legal affairs and customer service.

An objective hierarchy with the following five main top-level objectives was built: Delivery conditions and human resources, which accounts for how consistent and coherent the human resources allocated to the services are; Technical merit and resources, which it is an important efficiency factor leading to a significant reduction in labor cost; Price, which represents the lowest price offered by suppliers; Quality control procedures, which accounts for accredited quality certifications and how quality systems and procedures are deployed; and Graffiti prevention and cleanup, which is one of the most common incidents detracting from the appearance of the underground buildings. Twenty-one lowest-level objectives were included in the above objective hierarchy, see Fig. 6, and the corresponding attributes were established to indicate to what extent they were achieved by the respective offers.

Following the European Community directives, stating that criteria should be set and at least ordered by importance before examining the offers, DM preferences were quantified before identifying offers. Fig. 7 illustrates attribute weights. The most important attribute in the decision was Price, with an average normalized weight of 0.513 , followed at a distance by workload, quantity of technical means, number of quality certifications, experience with graffiti and workload allocation, with average normalized weights of $0.125,0.082,0.052$, 0.052 and 0.036 , respectively.

Next, the feasible supplier offers were identified and measured in terms of the 21 attributes. The performances for the six offers considered and the component utilities assessed are reported in (Jiménez et al., 2007). Note that uncertainty about some of the performances was accounted for by means of percentage deviations, which represent tolerances or correction factors for offers where information provided by the bidders was somewhat ambiguous or was not clear enough.

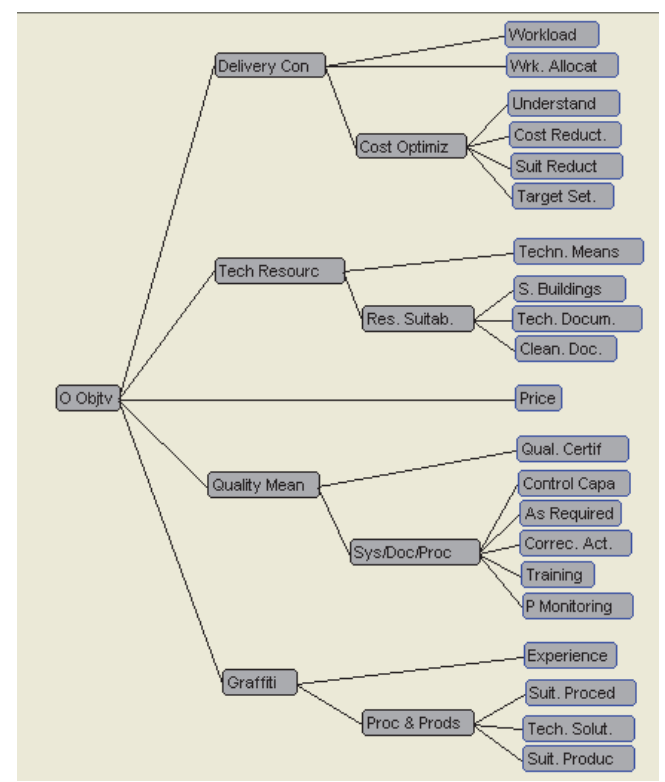

Fig. 6. Objective hierarchy in the selection of a supplier for cleaning services 
The additive model was then used to evaluate the offers under consideration, see Fig. 8 . Offers 3 and 6 were the best and worst ranked tenders. Looking at the utility intervals, we could discard offer 6 , because its maximum utility was lower than the minimum utility of offer 2. Consequently, we concluded that it was dominated. Although offer 3 appeared to be the most highly recommended, however, the overlapped utility intervals were examined in more detail through SA.
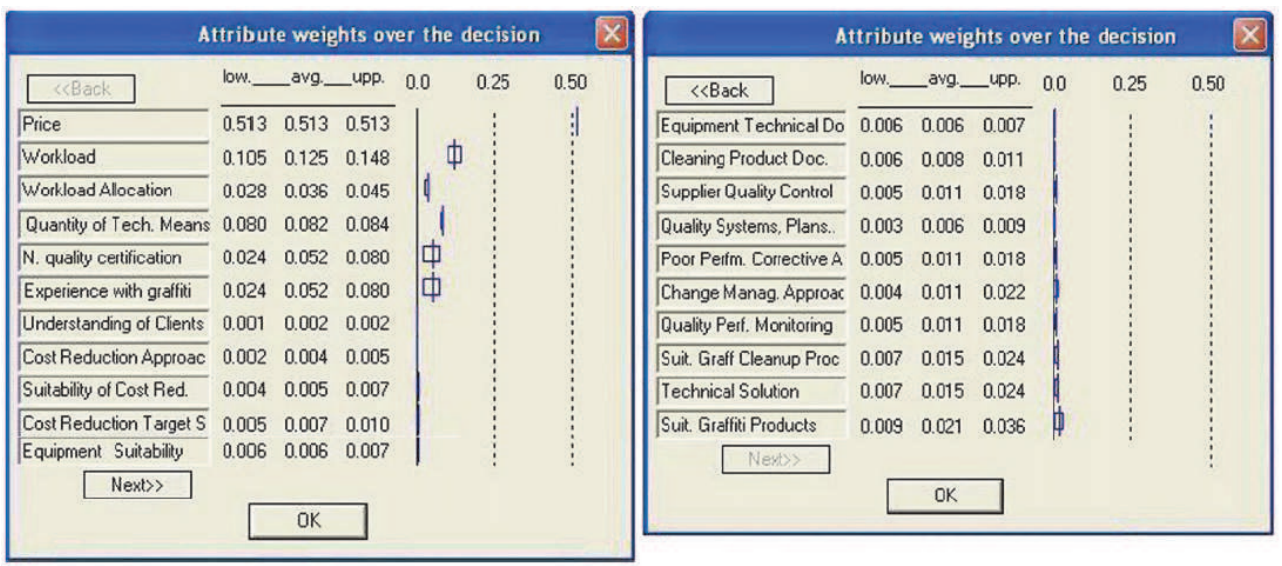

Fig. 7. The attribute weights in the selection of a supplier for cleaning services

First, the stability interval for all objectives throughout the hierarchy were computed, i.e., the interval where the average normalized weight for any objective can vary without the best ranked offer changing. The resulting stability intervals for all objectives throughout the hierarchy were [0,1], which meant that, whatever their relative importance, offer 3 remained the best-ranked tender, except for Delivery conditions and human resources, and Quality control procedures with stability weight intervals [0, 0.598] and [0, 0.748], respectively. Taking into account that the narrower a stability weight interval is the more sensitive the offers ranking is, we concluded that the offers ranking was robust regarding the elicited weights.

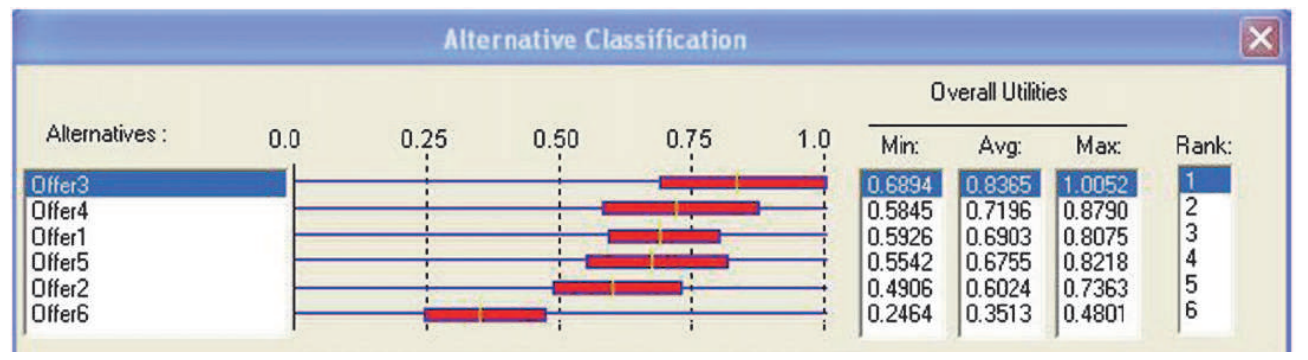

Fig. 8. Offer evaluation

On the other hand, only offer 3 was non-dominated and potentially optimal, so we could definitively conclude that it is the best offer. Monte Carlo simulation techniques were performed led to the same finding; offer 3 was the best. 


\subsection{Selection of segment to be sourced from low cost countries for a global industrial equipment manufacturer}

Another complex decision-making problem in which the GMAA system was to select segments to be sourced from low cost countries for a global industrial equipment manufacturer (Jiménez et al., 2005).

Competitive pressures are forcing companies to reduce their overall costs, while delivering faster and more diverse product portfolios to be more responsive to customers and competitors. In response to these pressures, companies are increasingly taking advantage of the opportunity to source from low cost countries (LCC) to achieve significant savings and give their organizations a competitive advantage. For a global industrial equipment manufacturer with material costs accounting for about $50 \%$ of the value of its final products, sourcing performance is crucial to original equipment manufactured (OEM) competitiveness.

Even though multinational companies have been sourcing from LCC for many years, purchasing in these regions is often very risky, and many companies spend a lot of time and energy trying to identify and minimize these risks (identifying reliable sources, political instability, currency risks, longer lead-times, more complex logistics, different/non-existent legal structures...).

Typically, incremental cost reductions of $15 \%-20 \%$ can be achieved by sourcing from LCC. Before moving the supply source for some specific segment categories to these regions, however, the segments have to be proven to have a comprehensive risk assessment, balanced against potential for lower costs. Although benefits are compelling, they come with significant challenges.

For the purpose of determining segment categories with the highest profit potential for sourcing from LCC, a range of conflicting criteria were taken into account simultaneously. Therefore, the promise of significant cost reductions was not the only consideration, and the country, industry and supplier risks were key factors considered during the prioritization of the category segments. In this case, the responsible organization of procurement evolved into a formal decision process, and other strategic issues related to LCC sourcing activities were quantified and formally incorporated into the analysis. This way, cost-cutting potential was only one of the purchaser's objectives.

As shown in Fig. 9, the Overall Objective (O.Objtv) was split into two main sub-objectives: Potential Benefits (Pot. Benefit) and Risks (Risk). Potential Benefits were measured in terms of four sub-objectives. The Total annual expenditure (Spend HCC) on all parts in the segment not sourced from LCC. The expenditure is an indicator of the potential volume with which we are dealing. The higher the expenditure is, the more room there is for savings. The Price per $\mathrm{kg}$ (Price Kg.) indicates the price regarding the value-added for the parts produced in high cost countries (HCC). A higher HCC price/kg value-added represents a high potential benefit. The Factor cost content (F C Content) is subject to comparison between HCC and LCC. Labor is the main factor cost to be taken into account. The higher the labor content is, the larger the cost difference window between sourcing countries is. High labor content represents potential high cost savings when sourcing from LCC. Finally, Supplier switching costs (Sup. S Costs) is the cost of switching from the current supplier set-up to a new supplier. The higher the switching cost, the lower the potential benefit. Tooling cost is the most important and most easily quantifiable switching cost to be accounted for. Other switching costs can be considered if known. 
On the other hand, Risks is split into four sub-objectives. Complexity of parts (Complx Parts) represents part of the risk of selecting a new supplier. Technical issues related to quality and material specification could be added to the assessment of the total complexity of parts in each segment. A higher complexity implies a higher risk. Risk with current suppliers (Risk C Suppl) quantifies the number of segments that the supplier is supplying at that moment. Moving business in one segment from the current supplier to LCC will influence the supply of the other segments (price increases, production stop pages, low performance, etc.). Therefore, the more segments supplied by one supplier, the higher the risk of moving to LCC.

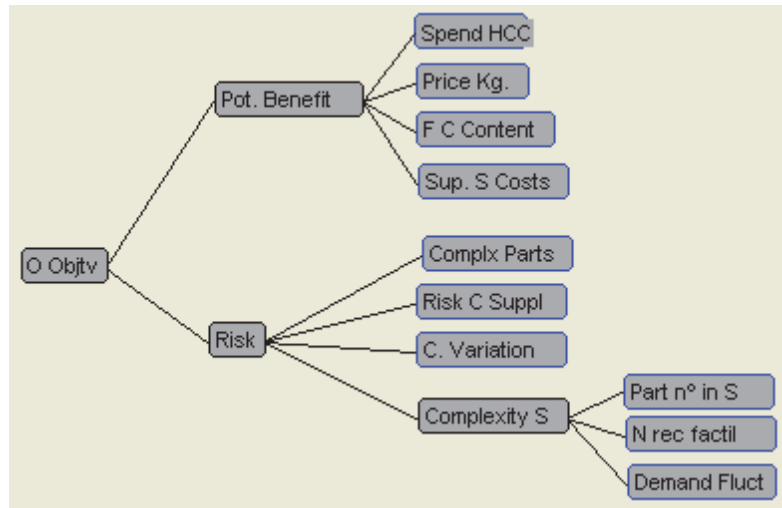

Fig. 9. Objective hierarchy to create a cost efficient production process

The Coefficient of variation (C. Variation) tells us how homogeneous the price per $\mathrm{kg}$ of the parts in the segment is. The higher the coefficient of variation, the greater the risk, because the handling of the different parts of the segment varies more. Finally, Complexity of segments (Complexity S) represents supply chain issues in relation to the purchase of parts from a wider perspective. The Number of parts within a segment (Part $\mathrm{n}^{\circ}$ in $\mathrm{S}$ ), the Number of receiving facilities for the parts in the segment ( $\mathrm{N}$ rec facil) and Demand fluctuation (Demand Fluct) are the main quantifiable criteria to be taken into consideration. A set of 19 non-metallic product segments was identified. Their performances in terms of the 10 attributes under consideration are reported in (Table 2, Jiménez et al., 2005).

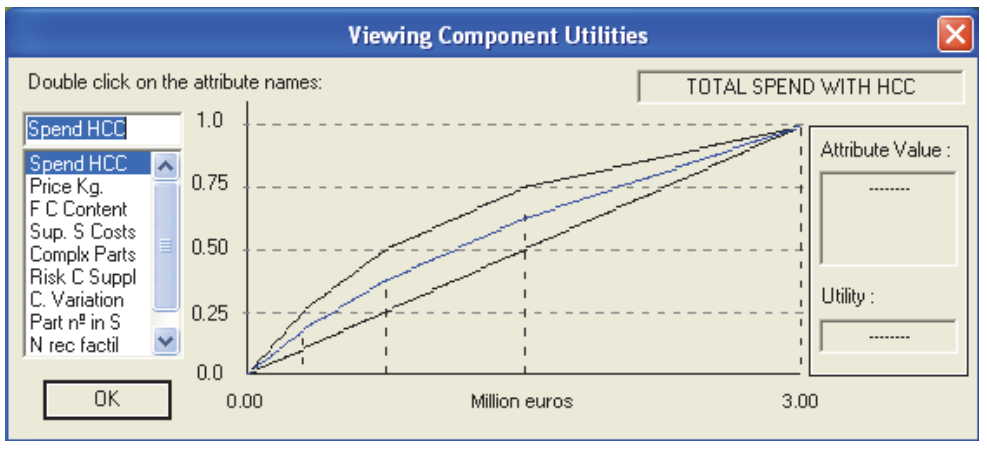

Fig. 10. Imprecise linear piecewise utility function for the Total annual expenditure 
Fig. 10 shows the assessed imprecise linear piecewise utility function for the Total annual expenditure (Spend HCC), whereas Fig. 11 shows the attribute weights for the decision.

Fig. 12 shows the ranking of segments derived from the additive multi-attribute utility model. SG19, SG11, SG18 and SG13 are the best-ranked segments, with average overall utilities of $0.6963,0.6835,0.5877$ and 0.5417 , respectively; whereas SG9, SG4 and SG5 are the worst ranked segments, with average overall utilities of $0.3833,0.3716$ and 0.3213 . Although SG19 appears to be the most highly recommended segment, sensitivity analysis (SA) should be used to examine the overlapped utility intervals (ranking robustness) in a more detail.

\begin{tabular}{|c|c|c|c|c|c|c|c|c|}
\hline \multicolumn{8}{|c|}{ Attribute weights over the decision } & \multirow{2}{*}{$\frac{\underline{x}}{1.0}$} \\
\hline <<Back & low. & _avg._ & -upp. & 0.0 & 0.25 & 0.50 & 0.75 & \\
\hline Total Spend with HCC & 0.170 & 0.170 & 0.170 & & & & & \\
\hline$\longdiv { \text { HCC Price per kilograme } }$ & 0.097 & 0.097 & 0.097 & & & & & \\
\hline Factor Cost Content & 0.170 & 0.195 & 0.220 & & Ф & & & \\
\hline Supplier Switching Costs & 0.024 & 0.036 & 0.049 & 4 & & & & \\
\hline Complexity of parts & 0.170 & 0.170 & 0.170 & & & & & \\
\hline Risks current suppliers & 0.024 & 0.036 & 0.049 & 4 & & & & \\
\hline Coefficient of Variation & 0.097 & 0.097 & 0.097 & & & & & \\
\hline Part $n^{0}$ in the segments & 0.039 & 0.039 & 0.039 & & & & & \\
\hline N⿳亠 of receiving facilit. & 0.097 & 0.039 & 0.097 & & & & & \\
\hline Demand fluctuation & 0.049 & 0.058 & 0.068 & $\phi$ & & 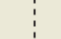 & 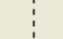 & ? \\
\hline Nexty> & & & & & & & & \\
\hline
\end{tabular}

Fig. 11. Attribute weights in the selection of segment to be sourced from low cost countries

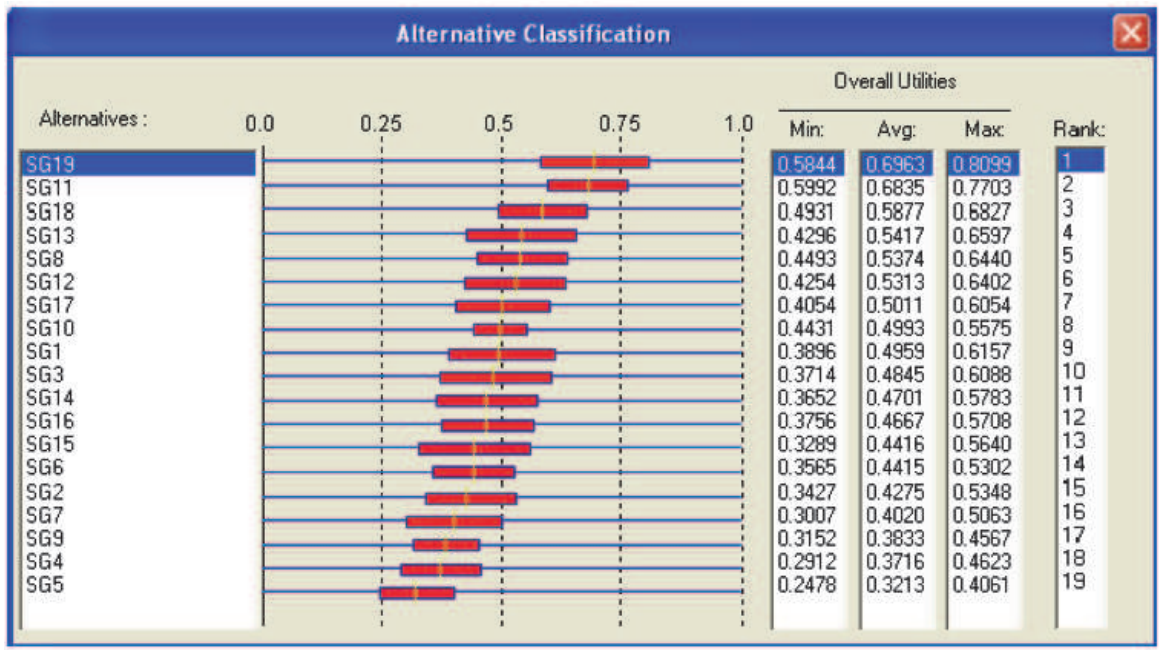

Fig. 12. Ranking of segment to be sourced from low cost countries

Only three segments, SG11, SG18 and SG19, are non-dominated and potentially optimal. Note that these were the best-ranked segments. Looking at the box plots output by Monte 
Carlo simulation techniques for SG11, SG18 and SG19, we found that they are always ranked second, third and first, respectively, see Fig. 13. Therefore, we concluded that the segment category with the best tradeoff between potential benefit and risks to be sourced from LCC was SG19: Hand lay-up composite parts. However, we were not just interested in the best segment to be sourced from LCC, our aim was to identify a segment set with a good enough tradeoff between potential benefit and risk.

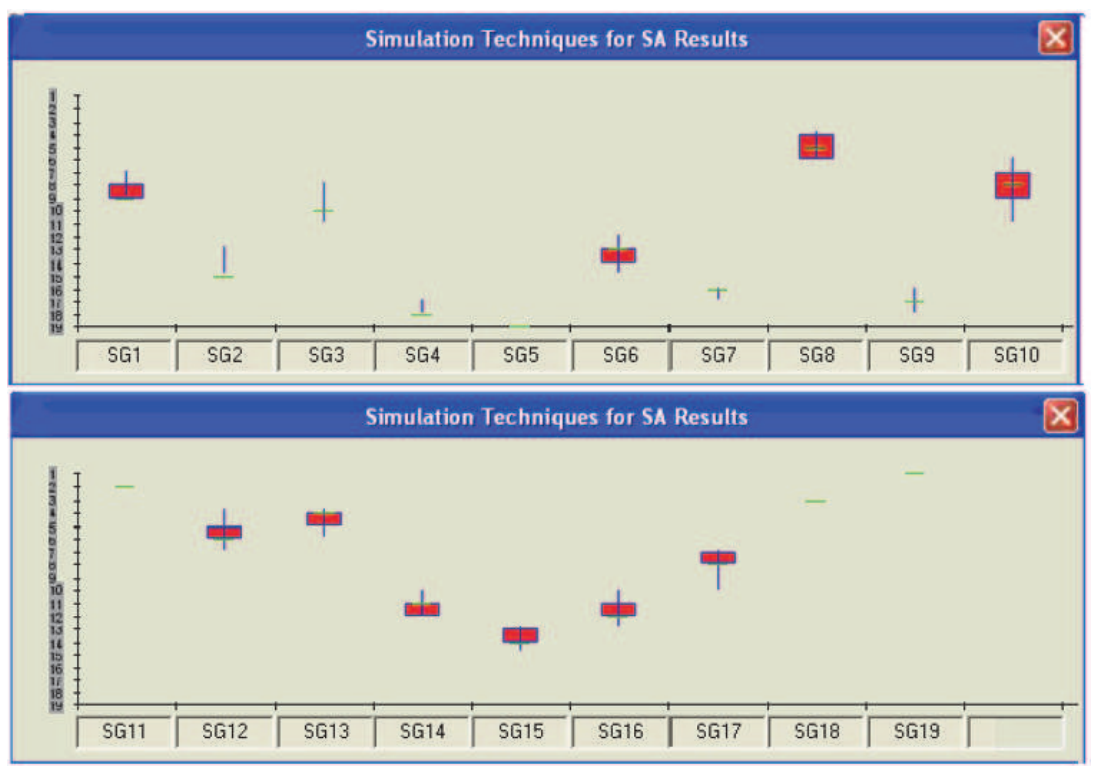

Fig 13. Results of Monte Carlo simulation techniques for the considered segments

\begin{tabular}{|c|c|c|c|c|c|c|c|}
\hline \multirow[b]{2}{*}{ Rank } & \multirow[b]{2}{*}{ Alternatives } & \multicolumn{3}{|c|}{ Overall Utilities } & \multirow[b]{2}{*}{ Total Spend w/HCC } & \multirow[b]{2}{*}{$\%$ spend } & \multirow[b]{2}{*}{ Cumm \% } \\
\hline & & Min: & Avg: & Max: & & & \\
\hline 1 & $\overline{\mathrm{SG} 19}$ & $0.584 \overline{421}$ & $\overline{0.696259}$ & $\overline{0.809 \overline{95}}$ & $\overline{2}, \overline{30}$ & $\overline{6}, 78 \%$ & $\overline{6,78 \%}$ \\
\hline 2 & SG11 & 0.599205 & 0.683484 & 0.770322 & 5,10 & $15,03 \%$ & $21,81 \%$ \\
\hline 3 & SG18 & 0.493066 & 0.587714 & 0.682714 & 3,94 & $11,61 \%$ & $33,42 \%$ \\
\hline 4 & SG13 & 0.429618 & 0.541691 & 0.659655 & 0,95 & $2.80 \%$ & $36,22 \%$ \\
\hline 5 & SG08 & 0.449297 & 0.537422 & 0.643996 & 0,75 & $2,21 \%$ & $38,43 \%$ \\
\hline 6 & SG12 & 0.425394 & 0.531276 & 0.640246 & 1,50 & $4,42 \%$ & $42,85 \%$ \\
\hline 7 & SG 17 & 0.405360 & 0.501112 & 0.605404 & 2,49 & $7,34 \%$ & $50,19 \%$ \\
\hline 8 & SG10 & 0.443123 & 0.499324 & 0.557503 & 4,75 & $14,00 \%$ & $64,19 \%$ \\
\hline$\overline{9}$ & SG01 & 0.389639 & 0.495854 & 0.615723 & 1,73 & $5,10 \%$ & $69, \overline{29} \%$ \\
\hline 10 & $\mathrm{SG} 03$ & 0.371448 & 0.484540 & 0.608774 & 0,72 & $2,12 \%$ & $71,41 \%$ \\
\hline 11 & SG14 & 0.365216 & 0.470133 & 0.578293 & 0,64 & $1,89 \%$ & $73,30 \%$ \\
\hline 12 & SG16 & 0.375603 & 0.466701 & 0.570811 & 1,58 & $4,66 \%$ & $77,95 \%$ \\
\hline 13 & SG15 & 0.328941 & 0.441557 & 0.564017 & 1,49 & $4,39 \%$ & $82,35 \%$ \\
\hline 14 & SG06 & 0.356492 & 0.441473 & 0.530208 & 0,91 & $2,68 \%$ & $85,03 \%$ \\
\hline 15 & SG02 & 0.342685 & 0.427510 & 0.534785 & 1,07 & $3,15 \%$ & $88,18 \%$ \\
\hline 16 & SG07 & 0.300710 & 0.401960 & 0.506272 & 0,63 & $1,86 \%$ & $90,04 \%$ \\
\hline 17 & SG09 & 0.315248 & 0.383333 & 0.456682 & 0,65 & $1,92 \%$ & $91,95 \%$ \\
\hline 18 & SG04 & 0.291185 & 0.371589 & 0.462338 & 1,20 & $3,54 \%$ & $95,49 \%$ \\
\hline 19 & SG05 & 0.247849 & 0.321267 & 0.406146 & 1,53 & $4,51 \%$ & $100,00 \%$ \\
\hline
\end{tabular}

Fig. 14. Final recommendation 
Taking into account the above segments' rankings and the results of SA, the OEM management finally recommended the best ranked segments, accounting for the $60 \%$ of the total expenditure on non-metallic category segments, to be sourced from LCC, see Fig. 14 .

\subsection{Selection of intervention strategies against eutrophication and the drastic decrease in the bird population in a fjord}

DSS are also becoming increasingly popular in environmental management (Stam et al., 1998; Tecle et al., 1998; Ito et al., 2001; Poch et al. 2004). Examples where MAUT has been used for environmental management problems can be found, e.g., in the field of forest management (Ananda \& Herath, 2009), natural resource management (Mendoza \& Martins, 2006)), different fields of water management (Linkov et al., 2006; Joubert et al., 2003), river management (Reichert et al., 2007; Corsair et al., 2009), landscape ecology (Geneletti, 2005), evaluation of farming systems (Prato \& Herath, 2007), and site selection for hazardous waste management (Merkhofer et al., 1997).

Many coastal zones all over the world have been put under increasing pressure from human activities over recent decades, through overfishing, nutrient inputs, and global warming. A related challenge is to come up with models that can accurately predict ecosystem changes from human activity and preventive or remedial actions. In this sense, the GMAA was also used to select intervention strategies against eutrophication and the drastic decrease in the bird population in Ringkøbing Fjord (Bryhn et al., 2009; Jiménez et al., 2011).

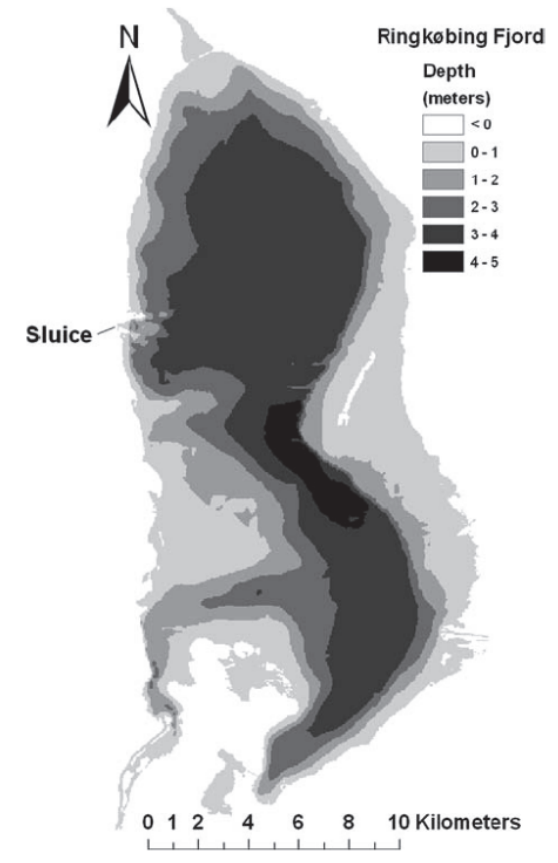

Fig. 15. Ringkøbing Fjord

Ringkøbing Fjord is a large and shallow brackish lagoon on the west coast of Denmark. It has an area of $300 \mathrm{~km}^{2}$, a volume of $0.57 \mathrm{~km}^{3}$, a maximum depth of $5.1 \mathrm{~m}$ and a mean depth 
of $1.9 \mathrm{~m}$. The lagoon receives large $\left(2 \mathrm{~km}^{3} \mathrm{yr}^{-1}\right)$ freshwater inputs from the catchment, as well as saltwater inputs through a sluice that connects the lagoon to the sea, see Fig. 15.

Ringkøbing Fjord has gone through two environmental regime shifts during the last decades (Håkanson et al., 2007), which has stirred up public sentiment in the area, mainly because of the disappearance of waterfowl.

The nine considered intervention strategies consisted of the abatement of nitrogen and/or phosphorous, the construction and maintenance of a saltwater dumping station or a second sluice to increase the water exchange between the lagoon and the outside sea and some combinations of the above. All of them were aimed at achieving good water quality in terms of trophic state and conditions for waterfowl and were compared with the no action alternative and with decreasing the salinity level to 7.2 per thousand, the mean value in the lagoon during the 12-year period preceding a major structural regime shift in 1996 (Håkanson \& Bryhn, 2008; Petersen et al., 2008).

Intervention strategies were evaluated considering their environmental, social and economic impacts. There were two attributes stemming from the environmental impact, natural TRIX deviation and number of birds. The degree of eutrophication in a coastal area can be expressed as a TRIX (TRophic state Index) deviation from the background value. The attribute associated with this lowest-level objective represented the average TRIX deviation regarding previous years over a 20-year period.

Another environmental impact we took into account was related to the sharp fall in birddays over the year in recent decades. The associated attribute accounted for the number of birds representing the average number of Bewick's swans and pintails living in the lagoon in a year for the time period under consideration.

Regarding the social impact we made a distinction between the social impact for critical population, i.e., people living around the lagoon that may be affected by the application of intervention strategies, and collective social impact. Both subjective attributes account for aspects like sentiment, possible employment associated with strategy application, crop image...

Finally, the economic impact was computed by the average costs concerning the intervention strategy application, i.e., nutrient abatement costs and/or construction and maintenance costs for facilities.

Note that while the models or experts initially provided precise performances, imprecision was introduced by means of an attribute deviation of $10 \%$ to evaluate the robustness of the evaluation (see Table 4 in Jiménez et al., 2011).

Next, DM's preferences were quantified accounting for ecocentric, anthropocentric and taxrefuser perspectives, which lead to different weight sets, and, finally, Monte Carlo simulation techniques were applied. Fig. 16 shows the resulting multiple boxplot from both perspectives.

Looking at the multiple box plots for the ecocentric and anthropocentric perspectives, we find that S5: Sluice and S9: No action are ranked highest in both boxplots. S8: 33\% P abatement + Sluice is ranked highest from the ecocentric viewpoint, but its best ranking from the anthropocentric perspective is fifth. Finally, S6: Salt7.2, with a best ranking of second from the anthropocentric viewpoint, is ranked as the worst strategy from the ecocentric perspective. S5: Sluice and S9: No action look better than the others. Moreover, the average rankings for both are 1.011 and 2.489 from the ecocentric perspective, respectively, and 1.531 and 1.605 from the anthropocentric viewpoint. These results are even consistent regarding the tax-refuser perspective, in which $S 5$ is better ranked (average ranking 1.246) than $S 9$ 
(average ranking 4.621). Thus, we arrived at the conclusion that S5: Sluice was the intervention strategy to be recommended.

Moreover, if we assume that there is no knowledge whatsoever of the relative importance of the attributes, i.e., weights for the attributes are generated completely at random, S5: Sluice was again the best intervention strategy throughout the simulation.

The same methodology was applied for different interest rates $(0,2,4,6$, and 8\%), and we arrived at the same conclusion that S5: Sluice is the intervention strategy to be recommended.

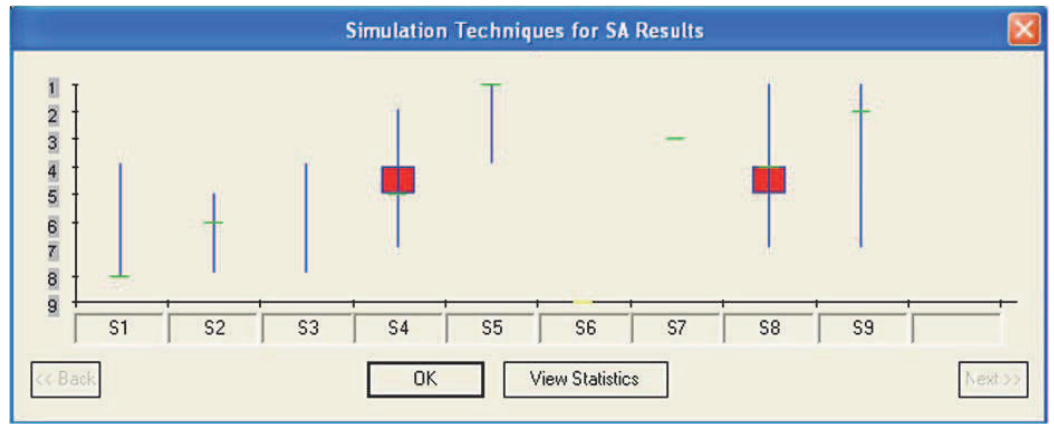

Ecocentrist perspective

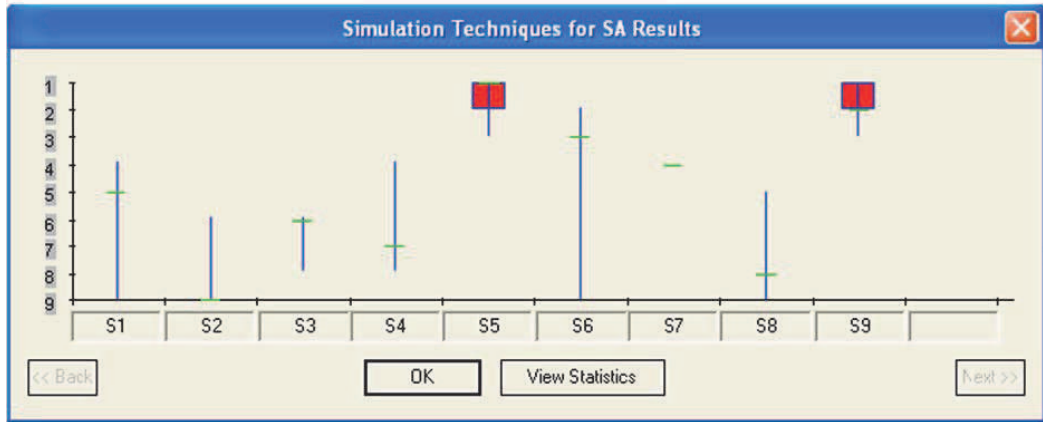

Anthropocentrist perspective

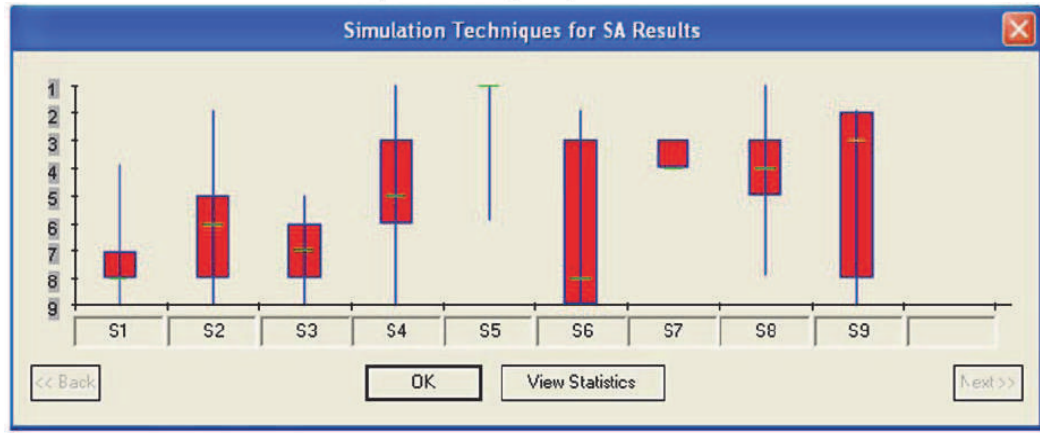

Tax-refuser perspective

Fig. 16. Strategy evaluation from different perspectives 


\section{Dominance measuring methods}

A recent approach for dealing with incomplete information about weights within MAUT is to use information about each alternative's intensity of dominance, known as dominance measuring methods.

Let us consider a group decision-making problem with $n$ attributes $\left(X_{i}, i=1, \ldots, n\right)$ and $m$ alternatives $\left(A_{j}, j=1, \ldots, m\right)$, where incomplete information about input parameters has been incorporated into the decision-making process as follows:

- Alternative performances under uncertainty $\left(x_{i} j \in\left[x_{i} L, x_{i} u\right], i=1, \ldots, n ; j=1, \ldots, m\right.$.

- Imprecision concerning utility function assessment $\left(u_{i}(\bullet) \in\left[u_{i} L(\bullet), u_{i} U(\bullet)\right], i=1, \ldots, n\right)$, where $u_{i}^{L}(\bullet)$ and $u_{i} U(\bullet)$ are the lower and the upper utility functions of the attribute $X_{i}$, and

- Imprecision concerning weights, which is represented by weights intervals $\left(w_{i} \in\right.$ $\left.\left[w_{i}^{L}, w_{i}{ }^{U}\right], i=1, \ldots, n\right)$.

Given two alternatives $A_{k}$ and $A_{l}$, alternative $A_{k}$ dominates $A_{l}$ if $D^{\prime}{ }_{k l} \geq 0, D^{\prime}{ }_{k l}$ being the optimum value of the optimization problem (Puerto et al., 2000),

$$
\begin{aligned}
D_{k l}^{\prime}=\min \left\{u\left(A_{k}\right)-u\left(A_{l}\right)\right. & \left.=\sum_{i=1}^{n} w_{i} u_{i}\left(x_{i}^{k}\right)-\sum_{i=1}^{n} w_{i} u_{i}\left(x_{i}^{l}\right)\right\} \\
w_{i}^{L} & \leq w_{i} \leq w_{i}^{U}, i=1, \ldots, n \\
x_{i}^{k L} & \leq x_{i}^{k} \leq x_{i}^{k U}, i=1, \ldots, n \\
x_{i}^{l L} & \leq x_{i}^{l} \leq x_{i}^{l U}, i=1, \ldots, n \\
\text { s.t. } \quad & u_{i}^{L}\left(x_{i}^{k L}\right) \leq u_{i}\left(x_{i}^{k}\right) \leq u_{i}^{U}\left(x_{i}^{k l}\right), i=1, \ldots, n \\
u_{i}^{L}\left(x_{i}^{l L}\right) & \leq u_{i}\left(x_{i}^{l}\right) \leq u_{i}^{U}\left(x_{i}^{l U}\right), i=1, \ldots, n
\end{aligned}
$$

This concept of dominance is called pairwise dominance and leads to the so-called dominance matrix:

$$
D=\left(\begin{array}{ccccc}
- & D_{11} & \ldots & D_{1 m-1} & D_{1 m} \\
D_{21} & D_{22} & \ldots & D_{2 m-1} & D_{2 m} \\
D_{31} & D_{32} & \ldots & D_{3 m-1} & D_{3 m} \\
& & \ldots & & \\
D_{m 1} & D_{m 2} & \ldots & D_{m m-1} & -
\end{array}\right)
$$

where $D_{k l}=D^{\prime}{ }_{k l} / \Sigma w_{i}$ and $D^{\prime}{ }_{k l}$ and $w_{i}$ are the optimum values for the objective function and weights in problem (2), respectively. The dominance matrix is the starting point of dominance measuring methods.

The first two dominance measuring methods were proposed in (Ahn \& Park, 2008). In the first, denoted AP1 (Ahn and Park 1), alternatives are ranked according to a dominating measure

$$
\alpha_{k}=\sum_{j=1, j \neq k}^{m} D_{k j}
$$

The higher this dominating measure is the more preferred the alternative will be, because the sum of the intensity of one alternative dominating the others will also be greater. In the 
second approach, denoted AP2 (Ahn and Park 2), alternatives are ranked according to the difference between the dominating measure $\alpha_{k}$ and a dominated measure

$$
\beta_{k}=\sum_{l=1, l \neq k}^{m} D_{l k}
$$

i.e., on the basis of $\alpha_{k}-\beta_{k}$.

Two new dominance measuring methods were proposed in (Mateos et al, 2011a). The first one, denoted DME1 (Dominance Measuring Extension 1), is based on the same idea as Ahn and Park suggested. First, dominating and dominated measures are computed from the paired dominance values and then a net dominance is derived. This net dominance is used as a measure of the strength of preference. DME1 computes the positive and negative dominating measures and positive and negative dominated measures. They are used to compute first a proportion representing how strongly one alternative is preferred to the others and second a proportion representing how intensely one alternative is not preferred to the others. Finally, DME1 subtracts both proportions to compute the intensity of the preference. DME1 can be implemented as follows:

1. Get the paired dominance values $D_{k l}$ and the dominance matrix $D$ as in (2).

2. Compute the dominating measures $\alpha_{k}, \alpha_{k}{ }^{+}$and $\alpha_{k}$ for each alternative $A_{k}$ :

$$
\alpha_{k}=\sum_{l=1, l \neq k}^{m} D_{k l}, \quad \alpha_{k}^{+}=\sum_{l=1, l \neq k, D_{k l}>0}^{m} D_{k l}, \quad \alpha_{k}^{-}=\sum_{l=1, l \neq k, D_{k l}<0}^{m} D_{k l}
$$

3. Compute the proportion

$$
P_{k}^{\alpha}=\frac{\alpha_{k}^{+}}{\alpha_{k}^{+}-\alpha_{k}^{-}} .
$$

4. Compute the dominated measures $\beta_{k}, \beta_{k}{ }^{+}$and $\beta_{k}$ - for each alternative $A_{k}$ :

$$
\beta_{k}=\sum_{l=1, l \neq k}^{m} D_{l k}, \beta_{k}^{+}=\sum_{l=1, l \neq k, D_{l k}>0}^{m} D_{l k}, \quad \beta_{k}^{-}=\sum_{l=1, l \neq k, D_{l k}<0}^{m} D_{l k}
$$

5. Compute the proportion

$$
P_{k}^{\beta}=\frac{\beta_{k}^{+}}{\beta_{k}^{+}-\beta_{k}^{-}} .
$$

6. Calculate the preference intensity value $P_{k}$ for each $A_{k}: P_{k}=P_{k}^{\alpha}-P_{k}^{\beta}, k=1, \ldots, m$.

7. Rank alternatives according to the $P_{k}$ values, where the best (rank 1 ) is the alternative for which $P_{k}$ is a maximum and the worst (rank $m$ ) is the alternative for which $P_{k}$ is the minimum.

The drawback of the DME1 method is that when the dominance matrix $D$ contains all negative elements, i.e., when all the alternatives are non-dominated, the algorithm is unable to rank the alternatives because they are all equal to 0 .

In the second method, denoted DME2 (Dominance Measuring Extension 2), alternatives are ranked on the basis of a preference intensity measure. Paired dominance values are first transformed into preference intensities $P I_{k l}$ (step 2) depending on the preference among 
alternatives $A_{k}$ and $A_{l}$. Then a preference intensity measure $\left(P I M_{k}\right)$ is derived for each alternative $A_{k}$ (step 3 ) as the sum of the preference intensities of alternative $A_{k}$ regarding the others alternatives. This is used as the measure of the strength of preference.

$D M E 2$ can be implemented as follows:can be implemented as follows:

1. Compute dominance matrix $D$ from the paired dominance values $D^{\prime}{ }_{k l}(2)$.

2. If $D_{k l} \geq 0$, then alternative $A_{k}$ is preferred to alternative $A_{l}$, i.e., the intensity with which alternative $A_{k}$ is preferred to $A_{l}$ is $1, P I_{k l}=1$.

Else $\left(D_{k l}<0\right)$ :

- If $D_{l k} \geq 0$, then alternative $A_{l}$ dominates alternative $A_{k}$, therefore, the intensity with which alternative $A_{k}$ is preferred to $A_{l}$ is 0 , i.e., $P I_{k l}=0$.

- $\quad$ Else note that alternative $A_{l}$ is preferred to alternative $A_{k}$ for those values in $\boldsymbol{W}_{\boldsymbol{k} l}$ (constraints of the optimization problem (2)) that satisfy $D_{k l} \leq \Sigma_{i} w_{i} u_{i}\left(x_{i}^{k}\right)-\Sigma_{i}$ $w_{i} u_{i}\left(x_{i}\right) \leq 0$, and $A_{k}$ is preferred to $A_{l}$ for those values in $W_{k l}$ that satisfy $0 \leq \Sigma_{i}$ $w_{i} u_{i}\left(x_{i}^{k}\right)-\Sigma_{i} w_{i} u_{i}\left(x_{i}^{l}\right) \leq-D_{l k} \Rightarrow$ the intensity $A_{k}$ is preferred to $A_{l}$ is

$$
P I_{k l}=\frac{-D_{l k}}{-D_{l k}-D_{k l}} .
$$

3. Compute a preference intensity measure for each alternative $A_{k}$

$$
P I M_{k}=\sum_{l=1, l \neq k}^{m} D P_{k l}
$$

Rank alternatives according to the PIM values, where the best (rank 1) is the alternative with greatest PIM and the worst is the alternative with the least PIM.

$D M E 1$ and $D M E 2$, like $A P 1$ and $A P 2$, considered ordinal relations regarding attribute weights, i.e., DMs ranked attributes in descending order of importance. For this scenario, Monte Carlo simulation techniques were carried out to analyze their performance and to compare them with other approaches, such as surrogate weighting methods (Stillwell et al., 1981; Barron \& Barrett, 1996) and adapted classical decision rules (Salo \& Hämäläinen, 2001).

The results showed that DME2 performs better in terms of the identification of the best alternative and the overall ranking of alternatives than other dominance measuring methods proposed by different authors. Also, DME2 outperforms the adaptation of classical decision rules and comes quite close to the rank-order centroid weights method, which was identified as the best approach.

Different cases with incomplete information about weights are considered in (Mateos et al., 2011b). Specifically, we consider weight intervals, weights fitting independent normal probability distributions or weights represented by fuzzy numbers (triangular and trapezoidal). A simulation study was also performed to compare the proposed methods with the measures reported in Ahn and Park, with classical decision rules and with the $S M A A$ and SMAA-2 methods in the above situations. The results show that DME2 and $S M A A-2$ outperform the other methods in terms of the identification of the best alternative and the overall ranking of alternatives.

\section{Conclusions}

Many complex decision-making problems have multiple conflicting objectives in the sense that further achievement in terms of one objective can occur only at the expense of some 
achievement of another objective. Therefore, preference trade-offs between differing degrees of achievement of one objective and another must be taken into account. Also, real problems are usually plagued with uncertainty, and it is impossible to predict with certainty what the consequences of each strategy under consideration will be. Formal analysis is required because it is very difficult to consider the above complexities informally in the mind.

The GMAA system is a DSS based on an additive multi-attribute utility model that is intended to allay many of the operational difficulties involved in a decision-making problem. It has been proven through the paper that it very useful to aid DMs in complex decision-making from a different nature, from the restoration of aquatic ecosystems contaminated by radionuclides to the selection of a supplier for cleaning services in an underground transportation company.

On the other hand, a recent approach to deal with imprecise information in multicriteria decision-making are the dominance measuring methods, which has been proved to outperform other approaches, like most surrogate weighting methods or the modification of classical decision rules to encompass an imprecise decision context. In this paper we have reviewed the main dominance measuring methods provided by different authors.

\section{Acknowledments}

The paper was supported by Madrid Regional Government project S-2009/ESP-1685 and the Spanish Ministry of Education and Science project TIN 2008-06796-C04-02.

\section{References}

Adelbratt, T. \& Montgomery, H. (1980), Attractiveness of Decision Rules, Acta Psychologica, Vol. 45, pp. 177-185, ISSN 0001-6918

Ahn, B.S. (2003). Extending Malakooti's Model for Ranking Multicriteria Alternatives with Preference Strength and Partial Information. IEEE Transactions on Systems, Management and Cybernetics, Part A: Systems and Humans, Vol. 33, pp. 281-287, ISSN 1083-4427

Ahn, B.S. \& Park, K.S. (2008). Comparing Methods for Multiattribute Decision Making with Ordinal Weights. Computers \& Operations Research, Vol. 35, pp. 1660-1670, ISSN 0305-0548

Ananda, J. \& Herath, G. (2009). A Critical Review of Multi-Criteria Decision Making Methods with Special Reference to Forest Management and Planning. Ecological Economics, Vol. 68, pp. 2535-2548, ISSN 0921-8009

Bana e Costa, C.A. (1986). Multicriteria Decision Aid Methodology to Deal with Conflicting Situations on the Weights. European Journal of Operational Research, Vol. 26, pp. 2234, ISSN 0377-2217

Bana e Costa, C.A. \& Vansnick, J.C. (2008). A Critical Analysis of the Eigenvalue Method used to Derive Priorities in AHP. European Journal of Operational Research, Vol. 187, pp. 1422-1428, ISSN 0377-2217

Barron, F. \& Barrett, B. (1996). Decision Quality Using Ranked Attribute Weights. Management Science, Vol. 42, No. 11, pp. 1515-1523, ISSN 1526-5501 
Brans, J.P. \& Mareschal, B. (2005). Promethee Methods, In: Multiple Criteria Decision Analysis. State of the Art Survey, J.R. Figueira, S. Greco and M. Ehrgott (Eds.), 112-131, Springer, ISBN 038723067X, New York, USA

Brans, J.P. \& Vincke, P.H. (1985). A Preference Ranking Organization Method - (the Promethee Method for Multiple Criteria Decision-Making). Management Science, Vol. 31, pp. 647-656, ISSN 0025-1909

Brans, J.P.; Vincke, P. \& Mareschal, B. (1986). How to Select and How to Rank Projects - the Promethee Method. European Journal of Operational Research, Vol. 24, pp. 228-238, ISSN 0377-2217

Bryhn, A.; Jiménez, A.; Mateos, A. \& Ríos-Insua, S. (2009). Multi-Attribute Analysis of Trophic State and Waterfowl Management in Ringkøbing Fjord, Denmark. Journal of Environmental Management, Vol. 90, No. 8, pp. 2568-2577, ISSN 0301-4797

Bucksaw, D. (2010). Decision Analysis Software Survey. OR/MS Today, Vol. 37, No. 6, pp. 4655, ISSN 1085-1038

Charnetski, J.R. \& Soland, R.M. (1978). Multiple-Attribute Decision Making with Partial Information: The Comparative Hypervolume Criterion, Naval Research Logistics Quaterly, Vol. 15, pp. 279-288, ISSN 0894-069X

Clemen, R.T. (1996). Making Hard Decisions, Duxbury Press, ISBN 0-534-92336-4, Belmont, USA

Corner, J.L. \& Kirkwood, C.W. (1991). Decision Analysis Applications in the Operations Research Literature, 1970-1989. Operations Research, Vol. 39, pp. 206-219, ISSN 15265463

Corsair, H.J.; Ruch, J.B.; Zheng, P.Q.; Hobbs, B.F. \& Koonce, J.F. (2009). Multicriteria Decision Analysis of Stream Restoration: Potential and Examples. Group Decision and Negotiation, Vol. 18, pp. 387-417, ISSN 0926-2644

Edwards, W. (1977). How to Use Multiattribute Utility Measurement for Social DecisionMaking. IEEE Transactions on Systems, Managements and Cybernetics, Vol. 7, No. 5, pp. 326-340, ISSN 1083-4427

Edwards, W. \& Barron, F.H. (1994). SMART and SMARTER: Inproved Simple Methods for Multiattribute Utility Measurement. Behaviour and Human Decision Processes, Vol. 60, pp. 306-325, ISSN 0749-5978

Eum, Y.; Park, K.S., \& Kim, H. (2001). Establishing Dominance and Potential Optimality in Multicriteria Analysis with Imprecise Weights and Values. Computers and Operations Research, Vol. 28, pp. 397-409, ISSN 0305-0548

Figueira, J.; Greco, S. \& Ehrgott, M. (eds.) (2005). Multiple Criteria Decision Analysis. State of the Art Surveys, Springer, ISBN 0-387-23067-X, New York, USA

Figueira, J.; Mousseau, V. \& Roy, B. (2005). Electre Methods, In: Multiple Criteria Decision Analysis. State of the Art Survey, J.R. Figueira, S. Greco and M. Ehrgott (Eds.), 133162, Springer, ISBN 038723067X, New York, USA

Geneletti, D. (2005). Formalising Expert Opinion Through Multi-Attribute Value Functions: An Application in Landscape Ecology. Journal of Environmental Management, Vol. 76, pp. 255-262, ISSN 0301-4797

Håkanson, L., \& Bryhn, A.C. (2008). Goals and Remedial Strategies for Water Quality and Wildlife Management in a Coastal Lagoon - A Case-Study of Ringkøbing Fjord, Denmark. Journal of Environmental Management, Vol. 86, pp. 498-519, ISSN 03014797. 
Håkanson, L.; Bryhn, A.C.\& Eklund, J.M. (2007). Modelling Phosphorus and Suspended Particulate Matter in Ringkøbing Fjord in Order to Understand Regime Shifts. Journal of Marine Systems, Vol. 68, pp. 65-90, ISSN 0924-79-63.

Hazen, G.B. (1986). Partial Information, Dominance and Potential Optimality in Multiattribute Utility Theory. Operations Research, Vol. 34, No. 2, pp. 296-310, ISSN 0030-364X

Ito, K.; Xu, Z.X.; Jinno, K.; Hojiri, T. \& Kawamura, A. (2001). Decision Support System for Surface Water Planning in River Basins. Journal of Water Resources Planning and Management, Vol. 127, pp. 272-276, ISSN 0733-9496

Jiménez. A., Ríos-Insua, S. \& Mateos, A. (2003). A Decision Support System for Multiattribute Utility Evaluation Based on Imprecise Assignments. Decision Support Systems, Vol. 36, No. 1, pp. 65-79, ISSN 0167-9236

Jiménez, A.; Rodríguez, L.C.; Ríos-Insua, S. \& Mateos, A. (2005). Selection of Segments to be Sourced from Low Cost Countries for a Global Industrial Equipment Manufacturer based on a Multi-Attribute Decision Support System. Research in Computing Science, Vol. 17, pp. 3-12, ISSN 1665-9899

Jiménez, A.; Ríos-Insua, S. \& Mateos, A. (2006). A Generic Multi-Attribute Analysis System. Computers \& Operations Research, Vol. 33, No. 4, pp. 1081-1101, ISSN 0305-0548

Jiménez, A.; Mateos, A.; Ríos-Insua, S. \& Rodríguez, L.C. (2007). Contracting of Cleaning Services in a European Underground Transportation Company with the Aid of a DSS. Decision Support Systems, Vol. 43, No. 4, pp. 1485-1498, ISSN 0167-9236

Jiménez, A.; Mateos, A. \& Brhyn, A. (2011). Selecting Intervention Strategies Against Eutrophication and the Drastic Decrease in Bird Abundance in Ringkøbing Fjord. TOP An Official Journal of the Spanish Society of Statistics and Operations Research (accepted, DOI: 10.1007/s11750-010-0136-x), ISSN 1134-5764

Joubert, A.; Stewart, T.J. \& Eberhard, R. (2003). Evaluation of Water Supply Augmentation and Water Demand Management Options for the City of Cape Town. Journal of Multi-Criteria Decision Analysis, Vol. 12, pp. 17-25, ISSN 1057-9214

Keefer, D.L.; Kirkwood, C.W. \& Corner, J.L. (2004). Perspective on Decision Analysis Applications, 1990-2001. Decision Analysis, Vol. 1, pp. 4-22, ISSN 1545-8490

Keeney, R.L. \& Raiffa, H. (1993). Decisions with Multiple Objectives: Preferences and Value Tradeoffs. Cambridge University Press, ISBN 0521438837, Cambridge, UK

Kirkwood, C.W. (1997). Strategic Decision Making: Multiobjective Decision Analysis with Spreadsheets, Duxbury, ISBN 0-534-51692-0, Beltmon, USA

Kirkwood, C.W. \& Sarin, R.K. (1985). Ranking with Partial Information: A Method and an Application. Operations Research, Vol. 33, pp. 38-48, ISSN 0030-364X

Kmietowcz, Z.W. \& Pearman, A.D. (1984). Decision Theory, Linear Partial Information and Statistical Dominance. Omega, Vol. 12, pp. 391-399, ISSN 0305-0483

Lahdelma, R. \& Salminen, P. (1998). SMAA - Stochastic Multiobjective Acceptability Analysis. European Journal of Operational Research, Vol. 106, pp. 137-143, ISSN 03772217

Lahdelma, R. \& Salminen, P. (2001). SMAA2 - Stochastic Multiobjective Acceptability Analysis for Group Decision Making. Operations Research, Vol. 49, pp. 444-454, ISSN 0030-364X 
Lee, K.; Park, K.S. \& Kim, H. (2002). Dominance, Potential Optimality, Imprecise Information, and Hierarchical Structure in Multi-criteria Analysis. Computers and Operations Research, Vol. 29, pp. 1267-1281, ISSN 0305-0548

Linkov, I.; Satterstrom, F.K.; Kiker, G.; Seager, T.P.; Bridges, T.; Gardner, K.H., Rogers, S.H.; Belluck, D.A. \& Meyer, A. (2006). Multicriteria Decision Analysis: A Comprehensive Decision Approach for Management of Contaminated Sediments. Risk Analysis, Vol. 26, pp. 61-78, ISSN 0272-4332

Malakooti, B. (2000). Ranking and Screening Multiple Criteria Alternatives with Partial Information and Use of Ordinal and Cardinal Strength of Preferences. IEEE Transactions on Systems, Management and Cybernetics, Part A: Systems and Humans, Vol. 30, pp. 787-801, ISSN 1083-4427

Mateos, A.; Jiménez, A. \& Blanco, J.F. (2011a). A MCDM Ranking Method Based on a Dominance Measure: Computational Study. Group Decision and Negotiation (submitted), ISSN 0926-2644

Mateos, A.; Jiménez, A. \& Blanco, J.F. (2011b). Dominance Measuring Method Performance under Incomplete Information about Weights. Journal of Multi-Criteria Decision Analysis (submitted), ISSN 1057-9214

Mateos, A.; Jiménez, A. \& Ríos-Insua, S. (2006). Monte Carlo Simulation Techniques for Group Decision-Making with Incomplete Information. European Journal of Operations Research, Vol. 174, No. 3, pp. 1842-1864, ISSN 0377-2217

Mateos, A.; Ríos-Insua, S. \& Jiménez, A. (2007). Dominance, Potential Optimality and Alternative Ranking in Imprecise Decision Making. Journal of Operational Research Society, Vol. 58, No. 3, pp. 326-336, ISSN 0160-5682

Mendoza, G.A. \& Martins, H. (2006). Multi-Criteria Decision Analysis in Natural Resource Management: A Critical Review of Methods and New Modelling Paradigms. Forest Ecology and Management, Vol. 230, pp. 1-22, ISSN 0378-1127

Merkhofer, M.W.; Conway, R. \& Anderson, R.G. (1997). Multiattribute Utility Analysis as a Framework for Public Participation in Siting a Hazardous Waste Management Facility. Environmental Management, Vol. 21, pp. 831-839, ISSN 0044-7447

Monte, L.; Kozhouharov, V.; Zheleznyak, M.; Kryshev, I.; Voitsekhovitch, O.; Brittain, J.; Gallego, E. \& Hakanson, L. (eds.) (2002). Implementing Computerised Methodologies to Evaluate the Effectiveness of Countermeasures for Restoring Radionuclide Contaminated Fresh Water Ecosystems. COMETES Project. Final Report RT/AMB/2001/2, Serie Ambiente, ENEA, Rome. ISSN 1120-5555

Monte, L.; van der Steen, J.; Bergstroem, U.; Gallego, E.; Brittain, J. \& Hakanson, L. (eds.) (2000). The Project MOIRA: A Model-Based Computerised System for Management Support to Identify Optimal Remedial Strategies for Restoring Radionuclide Contaminated Aquatic Ecosystems and Drainage Areas. Final Report RT/AMB/2000/13, Serie Ambiente, ENEA, Rome. ISSN 1120-5555

Nijkamp, P.; Rietveld, P. \& Voogd, H. (1990). Multicriteria Evaluation Physical Planning, North Holland, ISBN 0444881247, Amsterdam, The Netherlands

Park, K. (2004). Mathematical Programming Models for Characterizing Dominance and Potential Optimality when Multicriteria Alternative Values and Weights are Simultaneously Incomplete. IEEE Transactions on Systems, Management and Cybernetics, Part A: Systems and Humans, Vol. 34, pp. 601-614, ISSN 1083-4427 
Perez, J.; Jimeno, J.L. \& Mokotoff, E. (2006). Another Potential Shortcoming of AHP. TOP An Official Journal of the Spanish Society of Statistics and Operations Research, Vol. 14, pp. 99-111, ISSN 1134-5764

Petersen, J.K.; Hansen, J.W.; Brogaard Laursen, M.; Clausen, P.; Carstensen, J. \& Conley, D.J. (2008). Regime Shift in a Coastal Marine Ecosystem. Ecological Applications, Vol. 18, pp. 497-510, ISSN 1051-0761

Poch, M., Comas, J., Rodríguez-Roda, I.; Sánchez-Marré, M. \& Cortés, U. (2004). Designing and Building Real Environmental Decision Support Systems. Environmental Modeling \& Software, Vol. 19, No. 9, pp. 857-873, ISSN 1364 -8152

Prato, T. \& Herath, G. (2007). Multiple-Criteria Decision Analysis for Integrated Catchment Management. Ecological Economics, Vol. 63, pp. 627-632, ISSN 0921 -8009

Puerto, J.; Marmol, A.M.; Monroy, L. \& Fernández, F.R. (2000). Decision Criteria with Partial Information. International Transactions in Operational Research, Vol. 7, pp. 51-65, ISSN 1475-3995

Raiffa, H. (1982). The Art and Science of Negotiation. Harvard University Press, ISBN 0-67404813, Cambridge, UK

Reichert, P.; Borsuk, M.; Hostmann, M.; Schweizer, S.; Sporri, C.; Tockner, K. \& Truffer, B. (2007). Concepts of Decision Support for River Rehabilitation. Environmental Modelling \& Software, Vol. 22, pp. 188-201, ISSN 1364-8152

Ríos Insua, D. \& French, S. (1991). A Framework for Sensitivity Analysisin Discrete MultiObjective Decision-Making. European Journal of Operational Research, Vol. 54, pp. 176-190, ISSN 0377-2217

Ríos-Insua, S.; Jiménez, A. \& Mateos, A. (2004). A Time-Dependent Decision Support System for MultiAttribute Decision-Making. Integrated Computer-Aided Engineering, Vol. 11, No. 1, pp. 63-75, ISSN 1069-2509

Ríos-Insua, S.; Gallego, E.; Jiménez, A. \& Mateos, A. (2006). A Multi-Attribute Decision Support System for Selecting Environmental Intervention Strategies for Radionuclide Contaminated Freshwater Ecosystems. Ecological Modelling, Vol. 196, No. 1-2, pp. 195-208, ISSN 0304-3800

Roy, B. (1996). Multicriteria Methodology for Decision Aiding. Kluwer Academic Publishers, ISBN 079234166X, Dordrecht, The Netherlands

Saaty, T.L. (1980). The Analytic Hierarchy Process, MacGraw-Hill, ISBN 0070543712, New York, USA

Sage, A. \& White, C.C. (1984). Ariadne: a Knowledge-Based Interactive System for Planning and Decision Support. IEEE Transactions on Systems, Management and Cybernetics, Part A: Systems and Humans, Vol. 14, pp. 35-47, ISSN 1083-4427

Salo, A.A. \& Hämäläinen, R.P. (1995). Preference Programming through Approximate Ratio Comparisons. European Journal of Operations Research, Vol. 82, pp. 458-475, ISSN 0377-2217

Salo, A.\& Hämäläinen, R.P. (2001). Preference Ratio in Multiattribute Evaluation (PRIME) Elicitation and Decision Procedures under Incomplete Information. IEEE Transactions on Systems, Management and Cybernetics, Part A: Systems and Humans, Vol. 31, No.6, pp. 533-545, ISSN 1083-4427

Sarabando, P. \& Dias, L.C. (2010). Simple Procedures of Choice in Multicriteria Problems Without Precise Information About the Alternatives Values. Computers \& Operations Research, Vol. 37, No. 12, pp. 2239-2247, ISSN 0305-0548 
Stam, A.; Salewicz, K.A. \& Aronson, J.E. (1998). An Interactive Reservoir System for Lake Kariba. European Journal of Operational Research, Vol. 107, pp. 119-136, ISSN 03772217

Stewart, T.J. (1996). Robustness of Additive Value Function method in MCDM. Journal of Multi-Criteria Decision Analysis, Vol. 5, pp. 301-309, ISSN 1099-1360

Stillwell, W.G.; Seaver, D.A. \& Edwards, W.A. (1981). Comparison of Weight Approximation Techniques in Multiattribute Utility Decision Making. Organization Behavior and Human Decision Processes, Vol. 28, pp. 62-77, ISSN 0749-5978

Tecle, A.; Shrestha, B.P. \& Duckstein, L. (1998). A Multiobjective Decision Support System for Multiresource Forest Management. Group Decision and Negotiation, Vol. 7, pp. 23-40, ISSN 0926-2644

Voogd, H. (1983). Multicriteria Evaluation for Urban and Regional Planning, Pion Ltd., London, UK.

Wang, X. \& Triantaphyllou, E. (2008). Ranking Irregularities when Evaluating Alternatives by Using some ELECTRE Methods. Omega, Vol. 36, pp. 45-63, ISSN 0305-0483.

Weber, M. (1987). Decision Making with Incomplete Information. European Journal of Operational Research, Vol. 28, pp. 44-57, ISSN 0377-2217

von Winterfeldt, D. \& Edwards, W (1986), Decision Analysis and Behavioral Research, Cambridge University Press, ISBN 0521273048, Cambridge, UK

Zeithaml, V.A.; Parasuraman, A. \& Berry, L.L. (1990). Delivering Quality Service: Balancing Customer Expectations and Perceptions, The Free Press, ISBN 9780029357019, New York, USA. 


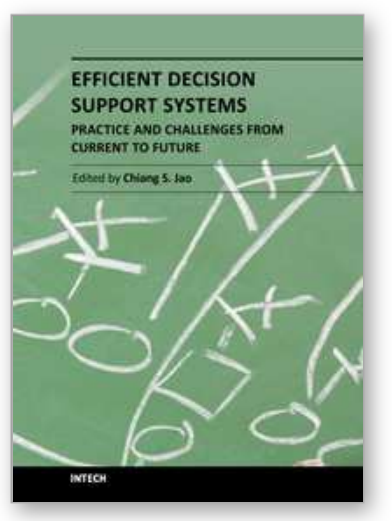

\section{Efficient Decision Support Systems - Practice and Challenges From Current to Future}

Edited by Prof. Chiang Jao

ISBN 978-953-307-326-2

Hard cover, 542 pages

Publisher InTech

Published online 09, September, 2011

Published in print edition September, 2011

This series is directed to diverse managerial professionals who are leading the transformation of individual domains by using expert information and domain knowledge to drive decision support systems (DSSs). The series offers a broad range of subjects addressed in specific areas such as health care, business management, banking, agriculture, environmental improvement, natural resource and spatial management, aviation administration, and hybrid applications of information technology aimed to interdisciplinary issues. This book series is composed of three volumes: Volume 1 consists of general concepts and methodology of DSSs; Volume 2 consists of applications of DSSs in the biomedical domain; Volume 3 consists of hybrid applications of DSSs in multidisciplinary domains. The book is shaped upon decision support strategies in the new infrastructure that assists the readers in full use of the creative technology to manipulate input data and to transform information into useful decisions for decision makers.

\section{How to reference}

In order to correctly reference this scholarly work, feel free to copy and paste the following:

Antonio Jiménez and Alfonso Mateos (2011). GMAA: A DSS Based on the Decision Analysis Methodology Application Survey and Further Developments, Efficient Decision Support Systems - Practice and Challenges From Current to Future, Prof. Chiang Jao (Ed.), ISBN: 978-953-307-326-2, InTech, Available from:

http://www.intechopen.com/books/efficient-decision-support-systems-practice-and-challenges-from-current-tofuture/gmaa-a-dss-based-on-the-decision-analysis-methodology-application-survey-and-further-developments

\section{INTECH}

open science | open minds

\section{InTech Europe}

University Campus STeP Ri

Slavka Krautzeka 83/A

51000 Rijeka, Croatia

Phone: +385 (51) 770447

Fax: +385 (51) 686166

www.intechopen.com

\section{InTech China}

Unit 405, Office Block, Hotel Equatorial Shanghai

No.65, Yan An Road (West), Shanghai, 200040, China

中国上海市延安西路65号上海国际贵都大饭店办公楼405单元

Phone: +86-21-62489820

Fax: $+86-21-62489821$ 
(C) 2011 The Author(s). Licensee IntechOpen. This chapter is distributed under the terms of the Creative Commons Attribution-NonCommercialShareAlike-3.0 License, which permits use, distribution and reproduction for non-commercial purposes, provided the original is properly cited and derivative works building on this content are distributed under the same license. 